the existing Journal of Composite Materials or Polymer Composites.

The presentation of the papers is not pretentious. There are wide variations in the standard of writing, in the diagrams and in the style of references. Editorial comment is restrained, if not nonexistent. Refereeing, if any, does not seem to be stringent, and papers are accepted within a day in some cases, but within a month on average. But, then, what does one expect for US\$32 an issue?

The rapid acceptance of papers is perhaps due to the fact that most of them are written by the editors. With a board of 24 editors, it is eminently possible that no other authors are required. Having said that, the editors are of high standing in the composites community. A bright future for the journal is possible if good papers with applied emphasis can be attracted, especially if the number of authors from industry can be increased from the pathetically low showing in the first four issues. There is certainly a niche for a composites journal with an applied emphasis.

Kevin Kendall is in the Department of Chemistry, University of Keele, Keele, Staffordshire ST5 5BG, UK.

\section{Free and essential}

\section{John Emsley}

Main Group Chemistry News. Editor John Vassallo. Gordon and Breach. 4/yr. University libraries \$193, corporate libraries \$305; free to individuals.

Contemporary Organic Synthesis. Chairman of editorial board G. Pattenden. Royal Society of Chemistry. 6/yr. Europe £165, USA \$303, elsewhere $£ 173$.

THERE is no reason for main-group inorganic chemists not to receive Main Group Chemistry News (MGCN), because it's free. All they have to do is contact the publishers, Gordon and Breach, and then four times a year they will receive a journal they can read while they eat their sandwiches. It will keep them well informed about the publisher's other journals and books targeted at main-group chemists. It also carries information about conferences, new products and the dates of forthcoming meetings.

Clearly, recipients of such a free sheet would soon start to discard it unopened, so something else is needed, something worth their reading. $M G C N$ provides it in the form of 'overviews', of which there are between two and five per issue, some as long as 12 pages.

In the edition of June 1995 there are overviews on dendrimers, which are polymers with the structure of exotic blossoms, and phosphorus-31 nuclear magnetic resonance, which is an important analytical technique. Both are of sufficiently high aca- demic standard for the recipient of $M G C N$ not only to read them but also to retain the issues for future reference. The only justification for a university librarian to subscribe to $M G C N$ would be to build up a complete set of these useful overviews - assuming there is a main-group chemist or two on campus.

On the other hand, almost every campus has organic chemists, so libraries will have to subscribe to Contemporary Organic Synthesis because almost every organic chemist researches organic synthesis. Chemists are finding that they can, given a lot of skill and a little cunning, synthesize even the most exotic molecules found in nature. Each issue of Contemporary Organic Synthesis carries four lengthy articles in which chemists in a particularly active field of organic chemistry review the recent literature. Such articles will be very useful to those starting a $\mathrm{PhD}$ or to researchers wanting a quick way into an area. Each review is about 15 pages long and covers about 150 original papers. The journal also has reviews of the more normal kind, where the focus is narrower. For example, in the issue of February 1995, Alexander Oxford, of Glaxo-Wellcome, deals with migraine, the role of serotonin and the use of sumatriptan to control it.

Each paper in Contemporary Organic Synthesis is headed by a list of subheadings, and there are plenty of clearly drawn molecular structures and reaction sequences. The overall impression is of a journal whose authors have been well briefed, and which is produced with care and attention to detail.

John Emsley is in the Department of Chemistry, Imperial College, London SW7 2AY, UK. His book The Consumer's Good Chemical Guide (W. H. Freeman) won this year's Rhône-Poulenc Science Book Prize.

\section{Academic wasteland}

\section{Jane Powell}

Journal of Waste Management and Resource Recovery. Editor P. C. Coggins. EPP. 4/yr. £49, \$59.

I GENERALLY find journals on waste management disappointing. Although I am sure that papers on "the oxidation of organic compounds in waste" are fascinating to some, for many they are of marginal interest. So I eagerly awaited the arrival of this new journal. With Chris Coggins as editor, a person certainly inclined towards policy issues, I looked forward not only to a good read but also to the discovery of a possible destination for my own research papers.

The first number begins not with an engaging leading article or welcoming address, but instead has something called 'Notes', an interesting enough review of current waste-management news that would have found a better home at the end of the issue. The papers, however, do not disappoint, covering a satisfactory mix of recycling issues, hazardous household waste collections, incineration economics, waste-management strategies and lifecycle assessment - inevitably rather predictable subjects for a new journal. In subsequent issues there is an emphasis on waste strategy and the upper end of the waste hierarchy (recycling for example), although papers on other disposal options are invited. (A challenge to the waste hierarchy would make for a refreshing read). The authors, however, are mainly consultants, or researchers primarily involved in consultancy. Where are the university researchers? Is waste-management research still not considered an academic subject?

The journal unquestionably fills a gap in the waste-management literature. The quality of production is good and we are told that papers received are reviewed promptly. But it needs to attract more academics if it is to establish itself as anything more than a promotional outlet for consultants.

Jane Powell is at the Centre for Social and Economic Research on the Global Environment, School of Environmental Sciences, University of East Anglia, Norwich NR4 7TJ, UK.

\section{Weather report}

\section{Jean Palutikof}

Meteorological Applications. Editor R. W. Riddaway. Royal Meteorological Society. 4/yr. USA, Canada and Mexico \$172, elsewhere $£ 96$.

IN the leaner and fitter economies of the 1980 s and $1990 \mathrm{~s}$, the savings to be achieved by appropriate exploitation of meteorological data are increasingly appreciated. A substantial community of researchers has emerged whose goal is to analyse these data for specific applications. Examples that come readily to mind include forecasting for ice formation on roads (to establish whether salting is necessary) and for the retail sector (to control the flow of goods to the shops).

Until the appearance of Meteorological Applications, this research community had no obvious forum for the presentation of results, particularly in Europe. The stated aim of the journal is to serve the complete range of interests within weather services: that is, according to the opening editorial in the inaugural issue, "all applied meteorologists, forecasters and users of 